\title{
Optical Limiting Study of Double Wall Carbon Nanotube-Fullerene Hybrids
}

\author{
Kang-Shyang Liao \\ University of Houston \\ Jun Wang \\ Trinity College Dublin \\ Daniel Fruchtl \\ Trinity College Dublin
}

See next page for additional authors

Follow this and additional works at: https://arrow.tudublin.ie/nanolart

Part of the Nanoscience and Nanotechnology Commons

\section{Recommended Citation}

Liao, K. et al. (2010) Optical Limiting Study of Double Wall Carbon Nanotube-Fullerene Hybrids. Chemical Physics Letters, Vol. 489, Issues 4-6, Pages 207-211. 9 April. doi:10.1016/j.cplett.2010.03.010

This Article is brought to you for free and open access by the NanoLab at ARROW@TU Dublin. It has been accepted for inclusion in Articles by an authorized administrator of ARROW@TU Dublin. For more information, please contact arrow.admin@tudublin.ie, aisling.coyne@tudublin.ie, gerard.connolly@tudublin.ie. Funder: US Department of Energy under Grant No. DEFG36-08G088008 and in part by the Science Foundation Ireland (SFI) under Grant No. 08/CE/I1432

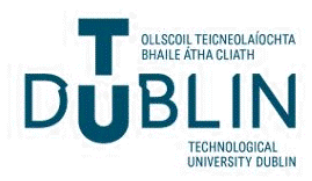




\section{Authors}

Kang-Shyang Liao, Jun Wang, Daniel Fruchtl, Nigel Alley, Enrico Andreoli, Eoghan Dillon, Andrew Barron, Hansoo Kim, Hugh Byrne, Werner Blau, and Seamus Curran 


\section{Optical Limiting Study of Double Wall Carbon}

\section{Nanotube-Fullerene Hybrids}

Kang-Shyang Liao, ${ }^{\mathrm{a}, *}$ Jun Wang, ${ }^{\mathrm{b}}$ Daniel Früchtl, ${ }^{\mathrm{b}}$ Nigel J. Alley, ${ }^{\mathrm{a}, \mathrm{c}}$ Enrico Andreoli, ${ }^{\mathrm{a}}$ Eoghan P.

Dillon, ${ }^{\mathrm{d}}$ Andrew R. Barron, ${ }^{\mathrm{d}}$ Hansoo Kim, ${ }^{\mathrm{e}}$ Hugh J. Byrne, ${ }^{\mathrm{f}}$ Werner J. Blau ${ }^{\mathrm{b}, \mathrm{g}}$ and Seamus A. Curran ${ }^{\mathrm{a}}$

${ }^{a}$ Institute for NanoEnergy, Department of Physics, University of Houston, Houston, Texas 77204, USA

${ }^{b}$ School of Physics and the Centre for Research on Adaptive Nanostructures and Nanodevices (CRANN), Trinity College

Dublin, Dublin 2, Ireland

${ }^{c}$ School of Physical Sciences, Dublin City University, Glasnevin, Dublin 9, Ireland.

${ }^{d}$ Richard E. Smalley Institute for Nanoscale Science and Technology, Center for Biological and Environmental

Nanotechnology, Carbon Nanotube Laboratory, Rice University, Houston, Texas 77005, USA

${ }^{e}$ Microscopy and Imaging Center, Texas A\&M University, College Station, TX 77843, USA

${ }^{f}$ Focas Institute, Dublin Institute of Technology, Dublin 8, Ireland

${ }^{9}$ School of Physics, Dublin Institute of Technology, Kevin Street, Dublin 2, Ireland

Corresponding Author:

Kang-Shyang Liao

kliao@mail.uh.edu

Institute for NanoEnergy, Department of Physics, 617 Science \& Research Building 1, University of Houston, Houston 77004, USA 
Tel: 1-713-743-3565; Fax: 1-713-743-3589

\section{Graphical Abstract}

The double wall carbon nanotube-Fullerene hybrids exhibit superior optical limiting performance to those of Fullerenes and CNTs.

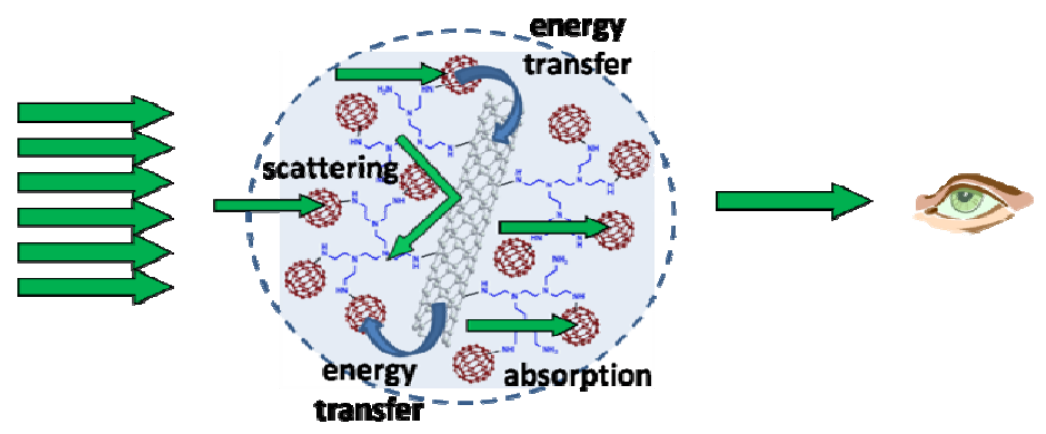




\begin{abstract}
In order to merge complementary temporal and spatial nonlinear optical characteristics of Fullerene and carbon nanotubes, synthesis of double wall carbon nanotube-Fullerene hybrid was performed by covalently linking DWNT and $\mathrm{C}_{60}$ by amination reaction with polyethylenimine. DWNT-Fullerene hybrids were characterized by thermogravimetric analysis, UV-vis spectroscopy and transmission electron microscopy. Optical limiting performance of DWNT-Fullerene hybrids is superior to those of Fullerenes and SWNTs at the same level $(\sim 80 \%)$ of transmission. Whereas nonlinear scattering is an evident mechanism, reverse saturable absorption from Fullerene moieties has significant contribution. Charge transfer between the DWNT and Fullerene moieties may play an important role of optical limiting.
\end{abstract}




\section{Introduction}

Recently, there has been increasing interest in the application of nanotechnology to protective coatings, including polymer nanotubular thin film composites. The use of carbon nanotubes in nanocomposites revealed a multiplicity of applications as nano-fillers in polymer hosts including thermal sensors [1] and antistatic coatings [2]. However, the success of nanocomposite fabrication is still dependent on developing reliable synthetic methods in forming their primary building blocks, a process that is challenging at the nanoscale for both inorganic and organic nanomaterials. Nonetheless, there have been significant advances in the use of nanocomposites in various optical applications, including organic light emitting diodes [3] and optical limiters [4]. Since the invention of lasers in the 1960s, not only have they become powerful instruments for material assessment, but are also commonly used in our daily life, such as surgery and telecom applications. Protection from lasers is consequently not a trivial matter but is one of genuine concern from a public safety and technological perspective. The development of optical limiting materials/devices provides a valuable solution to the dangers of lasers, as well as various other forms of optical instruments being used. A successful optical limiter should strongly attenuate intense, potentially dangerous laser beams, while exhibiting high transmittance for low intensity ambient light. Investigating optical limiting materials/mechanisms/ devices is therefore a very important area of research [5-8]. In the forefront of this field is a quest for ideal materials that include carbon nanomaterials [7,8], phthalocyanines [9,10], porphyrins [11], organometallics, inorganic semiconductors and liquid crystals [5,6]. In particular, the carbon nanomaterials: carbon black [12], fullerenes [13,14], carbon nanotubes (CNTs) [4,15-17] and graphenes [18] all make a great contribution to laser protection applications.

During the past two decades, researchers have established several effective nonlinear optical (NLO) mechanisms for optical limiting, namely, reverse saturable absorption (RSA), two-photon absorption (TPA), free-carrier absorption, nonlinear scattering and nonlinear refraction [5,8]. Fullerene- $\mathrm{C}_{60}$ is considered an ideal optical limiter across the visible spectrum (from 400 to $700 \mathrm{~nm}$ ) since it was first 
studied by Tutt and Kost [14]. The primary mechanism of optical limiting for $\mathrm{C}_{60}$ is $\mathrm{RSA}$, which involves formations of excited states (triplet-triplet) with an absorption cross section much larger than that of the ground state, leading to nonlinear absorption. More recent studies show CNTs have potential as a broadband optical limiter from 430 to $1064 \mathrm{~nm}[4,7,8,15]$. Thermally-induced nonlinear scattering and nonlinear refraction are found to be the dominant mechanisms. At low fluences, nonlinear scattering comes from solvent microbubbles generated by heat transfer from CNTs. At high fluences, the scattering is mainly due to formations of carbon microplasmas. Therefore, the superior optical limiting performance of CNTs can be attributed to their unique electronic structures that absorb broadband energy, as well as their large surface area that can effectively dispatch the energy to surrounding environments. In contrast to Fullerenes with a quick response time in the picosecond regime, CNTs generally respond at best in the nanosecond regime.

The development of nonlinear absorber-CNT hybrids by covalent or noncovalent combination has been reported by several groups [19-23]. In this work, we report the synthesis, characterization and optical limiting property of a covalent linked CNT-Fullerene hybrid. The hybrid is expected to merge complementary temporal and spatial NLO characteristics of Fullerene and carbon nanotubes, resulting in a viable optical limiting material satisfying most of requirements for laser protection.

\section{Experimental Methods}

Materials. DWNTs prepared using a CVD method (>95\% purity, O.D. of $4 \mathrm{~nm}$ and length of 5-20 $\mu \mathrm{m})$ were obtained from Nanolab. Transmission electron microscope (TEM) images revealed that the pristine DWNT sample is actually a mixture of SWNT, DWNT, TWNT and FWNT. Polyethylenimine (PEI, branched, $\left.M_{\mathrm{n}}=10,000 \mathrm{Da}\right), N, N$-dimethylformamide (DMF, anhydrous, 99.8\%), Fullerene-C 60 (98\%), chlorobenzene (anhydrous, 99.8\%) were obtained from Aldrich and used as received.

Direct Amination of DWNTs. DWNTs (3 g) and polyethylenimine $\left(M_{\mathrm{n}} \sim 10,000\right)(15 \mathrm{~g})$ were mixed in $250 \mathrm{~mL}$ of DMF. Sonication for $20 \mathrm{~min}$ and stirring at $50{ }^{\circ} \mathrm{C}$ for $5 \mathrm{~d}$ formed the product, DWNT-PEI 10,000. The resulting suspension was filtered through a $0.20 \mu \mathrm{m}$ nylon membrane and the precipitate 
was washed with $1 \mathrm{M} \mathrm{HCl}, 1 \mathrm{M} \mathrm{NaOH}$, water and methanol to remove any excess PEI. After drying, 5.5 $\mathrm{g}$ of the product was obtained. Characterization of the product was carried out by titration. A known amount of DWNT-PEI10,000 was added to $20 \mathrm{~mL}$ of $0.01 \mathrm{M} \mathrm{HCl}$. After sonicating the mixture for $1 \mathrm{~h}$ at $25{ }^{\circ} \mathrm{C}$, an aliquot $(5 \mathrm{~mL})$ of the resulting $\mathrm{HCl}$ solution was titrated to a $\mathrm{pH} 9.0$ endpoint using $0.01 \mathrm{M}$ $\mathrm{NaOH}$. The difference between the original amount of $\mathrm{HCl}$ and the amount of $\mathrm{HCl}$ titrated corresponded to the loading of titratable amino groups on DWNT-PEI10,000 and was 0.9 mequiv of titratable amine groups/g.

Synthesis of DWNT-PEI10,000-C60. DWNT-PEI10,000 (300 mg), Fullerene-C 60 (150 mg) and triethylamine $(0.5 \mathrm{~mL})$ were mixed in $20 \mathrm{~mL}$ of chlorobenzene. Sonication for $1 \mathrm{~min}$ and stirring at 100 ${ }^{\circ} \mathrm{C}$ for $5 \mathrm{~d}$ formed the product, DWNT-PEI10,000- $\mathrm{C}_{60}$. The resulting suspension was filtered through a $0.20 \mu \mathrm{m}$ nylon membrane and the precipitate was washed with chlorobenzene and methanol to remove any excess $\mathrm{C}_{60}$ and triethylamine. After drying, $408 \mathrm{mg}$ of the product was obtained.

Synthesis of PEI10,000- $C_{60}$. PEI10,000 $(50 \mathrm{mg})$, Fullerene- $\mathrm{C}_{60}(100 \mathrm{mg})$ and triethylamine $(1.0 \mathrm{~mL})$ were mixed in $10 \mathrm{~mL}$ of chlorobenzene. Sonication for $1 \mathrm{~min}$ and stirring at $100{ }^{\circ} \mathrm{C}$ for $5 \mathrm{~d}$ formed the product, PEI10,000- $\mathrm{C}_{60}$. The resulting suspension was filtered through a $0.20 \mu \mathrm{m}$ nylon membrane and the precipitate was washed with chlorobenzene and methanol until the filtrate became colorless. After drying, $122 \mathrm{mg}$ of the product was obtained.

Characterization. Thermogravimetric analysis (TGA) was recorded by SEIKO 1 TG/DTA 200 under Ar or air from 30 to $950{ }^{\circ} \mathrm{C}$. UV-vis spectra were recorded by an Ocean Optics HR2000+ high resolution spectrometer using a Mikropack PH-2000-BAL Deuterium-Halogen light source. High resolution micrographs were taken by an FEI TECNAI G2 20F transmission electron microscope. It was operated at a $200 \mathrm{kV}$ accelerating voltage, equipped with a $\mathrm{ZrO}_{2} / \mathrm{W}$ Schottky field emission gun and a Gatan imaging filter slow-scan CCD camera (GIF Tridiem with $2 \mathrm{k}$ x 2k pixels). Bright field TEM images were collected by the CCD camera of the TECNAI 20F.

Z-scan Measurement. NLO and optical limiting properties of DWNT-Fullerene hybrids were studied 
using open aperture Z-scan method, which is widely adopted to investigate third-order NLO processes, including nonlinear absorption, scattering and refraction. In this work, a Z-scan was performed using 6 ns pulses from a Q-switched Nd:YAG laser. After spatially removing higher-order modes, a laser beam was tightly focused with a $9 \mathrm{~cm}$ focal length lens. The laser was operated at its second harmonic, 532 $\mathrm{nm}$, with a repetition rate of $10 \mathrm{~Hz}$. Simultaneously, a focusing lens setup was arranged at $\sim 30^{\circ}$ to the direct incident beam to monitor the scattered light from the dispersions. All samples were tested in 1.0 cm quartz cells.

\section{Results and Discussion}

Syntheses and studies of CNT-fullerene hybrids have been reported [24,25]. D'Souza et al. performed syntheses of SWNT/Pyr- $\mathrm{NH}_{3}{ }^{+} /$crown- $\mathrm{C}_{60}$ hybrids by supramolecular assembly and studied their photoinduced electron transfer [24]. The results suggested a possibility of electron transfer from SWNTs to singlet excited Fullerenes in the hybrids. Wu et al. performed syntheses of grapevine SWNT-C 60 hybrids by covalent amide formation between oxidized SWNT and $\mathrm{C}_{60}$ derivative [25]. Characterizations revealed a ground-state electron-transfer trend from SWNT to $\mathrm{C}_{60}$ moieties in the grapevine nanostructure. Although these CNT-fullerene hybrids show great potential as materials for nonlinear optics, their syntheses are prohibitively complicated and time consuming. Here, we synthesized CNT-Fullerene hybrids using all commercial available reagents in only two steps. DWNTs are first treated with an excess amount of polyethylenimine (PEI) in $N, N$-dimethylformamide (DMF) at $50^{\circ} \mathrm{C}$ to give DWNT-PEI10,000 by following a procedure described by Liao et al [26]. Similar procedures were carried out by Dillon et al. for SWNT amination as well [27]. The PEI functionalized DWNTs can readily disperse in common organic solvents and the free amines on PEI functionalized DWNTs can act as nucleophiles. In the next step, DWNT-PEI10,000 was reacted with an excess amount of $\mathrm{C}_{60}$ in chlorobenzene at $100{ }^{\circ} \mathrm{C}$ for 5 days, as shown in Figure 1. Amination of Fullerenes was first studied by Hirsch et al [28] and it is suggested that amination of CNTs involves a similar mechanism as amination of Fullerenes [29]. 
Characterization of CNT-Fullerene hybrids included a series of chemical and physical analyses. Thermogravimetric analysis (TGA) under Ar showed distinct differences between the PEI derivative of DWNTs and starting DWNTs. As shown in Figure 2, as-received DWNTs exhibited a gradual weight loss of $10 \%$ over a temperature range $30-950{ }^{\circ} \mathrm{C}$. DWNT-PEI10,000 exhibited a $\sim 30 \%$ weight loss in the $250-350{ }^{\circ} \mathrm{C}$ temperature range. The weight loss in this region was ascribed to loss of the grafted PEI on DWNT samples. The TGA of DWNT-PEI10,000- $\mathrm{C}_{60}$ under Ar exhibited a $\sim 25 \%$ weight loss at the same temperature range, this represented the loss of grafted PEI. However, no extra weight loss was observed at higher temperature range. Presumably, both DWNT and $\mathrm{C}_{60}$ residue didn't burn under Ar. This hypothesis was proved by a separate TGA of PEI10,000- $\mathrm{C}_{60}$ under Ar over a temperature range 30$800{ }^{\circ} \mathrm{C}$ (data not shown). The TGA showed more than $60 \%$ of residue was left which can be ascribed to the $\mathrm{C}_{60}$ residue. In order to differentiate the composition of remaining residue of DWNT-PEI10,000- $\mathrm{C}_{60}$, the next TGA was first carried out under Ar from 30 to $500{ }^{\circ} \mathrm{C}$ to fully degrade PEI, air was then introduced to the heating chamber and the temperature was increased gradually to $650{ }^{\circ} \mathrm{C}$. A sudden drop of $\sim 25 \%$ weight was observed at $520^{\circ} \mathrm{C}$, followed by a more gradual weight loss of another $45 \%$ from 520 to $600{ }^{\circ} \mathrm{C}$. The first sudden drop was ascribed to the loss of $\mathrm{C}_{60}$ because all $\mathrm{C}_{60}$ molecules should burn at the same temperature. While the gradual weight loss from 520 to $600{ }^{\circ} \mathrm{C}$ can be ascribed to the loss of DWNT because it is dependent on the diameter and length of DWNTs. Each individual DWNT should burn gradually under different temperature ranges.

The formation of DWNT-Fullerene hybrids was also confirmed by UV-vis spectroscopy. As shown in Figure 3, relative to the spectrum of $\mathrm{C}_{60}$, the spectrum of DWNT-PEI10,000- $\mathrm{C}_{60}$ in chlorobenzene showed a maximum absorption of $330 \mathrm{~nm}$. The peak at $330 \mathrm{~nm}$ can be assigned to the allowed ${ }^{1} \mathrm{~T}_{1 \mathrm{u}} \rightarrow{ }^{1} \mathrm{~A}_{\mathrm{g}}$ transition of $\mathrm{C}_{60}$ [30]. Direct evidence of the formation of nanotube-fullerene hybrids can be seen through high resolution TEM micrographs as well. As shown in Figure 4, while the image of a pristine nanotube (left) shows a smooth surface covered with some amorphous carbon materials, a monomeric form of $\mathrm{C}_{60}$ spheres (right) can be clearly seen to be attached to the inner and outer surfaces 
of the SWNT in the image of the nanotube-fullerene hybrid.

For the optical limiting study, the hybrid was dispersed in chlorobenzene and poly $(m-$ phenylenevinylene-co-2,5-dioctoxyp-phenylenevinylene) (PmPV), respectively. PmPV is a well-known conjugated polymer used to disperse carbon nanotubes, resulting in property modified nanocomposites $[3,31]$. The normalized transmission and scattered light as functions of incident energy density was shown in Figure 5. As the incident energy density was increased, intense scattered light was observed from DWNT-Fullerene dispersions along with decreasing transmission. Therefore the nonlinear scattering, arising from DWNT moieties, is regarded as one of the main mechanisms for optical limiting. The mechanism leading to optical limiting effects in carbon nanotubes has been studied intensively. The induced scattering centers are composed of solvent bubbles and carbon microplasmas. Due to the solvent effect $[8,17]$, the hybrid dispersed in chlorobenzene possess superior optical limiting response and stronger scattered signal in comparison to the polymer dispersions. In addition, it is believable that RSA from Fullerene moieties has significant contribution as well. The superior optical limiting effect of the hybrids results from an accumulation of different mechanisms.

In order to evaluate the optical limiting ability of DWNT-Fullerene dispersions, we compare the optical limiting response of this hybrid with that of Fullerenes and SWNTs. As shown in Figure 6, the optical limiting performance of this hybrid is superior to those of Fullerenes and CNTs at the same level of transmission. Table 1 summarizes the linear and NLO coefficients for these three materials.

\section{Conclusion}

In summary, synthesis and characterization of DWNT-Fullerene hybrids was performed to merge complementary temporal and spatial NLO characteristics of Fullerene and carbon nanotubes. The optical limiting performance of DWNT-Fullerene hybrids is superior to those of Fullerenes and SWNTs at the same level of transmission. Future studies regarding mechanisms that contribute to this better optical limiting performance and the influence of covalent linkages between DWNTs and $\mathrm{C}_{60}$ to optical limiting are currently underway. 


\section{Acknowledgement}

The work is supported by the US Department of Energy under Grant No. DE-FG36-08GO88008 and in part by the Science Foundation Ireland (SFI) under Grant No. 08/CE/I1432. J.W. thanks SFI for his postdoctoral research fellowship.

\section{References}

[1] C. Li, E.T. Thostenson, T.-W. Chou, Compos. Sci. Technol. 68 (2008) 1227.

[2] S.A. Curran, D. Zhang, W.T. Wondmagegn, A.V. Ellis, J. Cech, S. Roth, D.L. Carroll, J. Mater. Res. 21 (2006) 1071.

[3] S.A. Curran, P.M. Ajayan, W.J. Blau, D.L. Carroll, J.N. Coleman, A.B. Dalton, A.P. Davey, A. Drury, B. McCarthy, S. Maier, A. Strevens, Adv. Mater. 10 (1998) 1091.

[4] P. Chen, X. Wu, X. Sun, J. Lin, W. Ji, K.L. Tan, Phys. Rev. Lett. 82 (1999) 2548.

[5] L.W. Tutt, T.F. Boggess, Prog. Quantum Electron. 17 (1993) 299.

[6] Y.-P. Sun, J.E. Riggs, Int. Rev. Phys. Chem. 18 (1999) 43

[7] Y. Chen, Y. Lin, Y. Liu, J. Doyle, N. He, X. Zhuang, J. Bai, W.J. Blau, J. Nanosci. and Nanotechnol. 7 (2007) 1268.

[8] J. Wang, W.J. Blau, J. Opt. A: Pure Appl. Opt. 11 (2009) 024001.

[9] S.M. O'Flaherty, S.V. Hold, M.J. Cook, T. Torres, Y. Chen, M. Hanack, W.J. Blau, Adv. Mater. 15 (2003) 19.

[10] J.J. Doyle, J. Wang, S.M. O'Flaherty, Y. Chen, A. Slodek, T. Hegarty, L. Carpenter II, D. Wöhrle, M. Hanack, W.J. Blau, J. Opt. A: Pure Appl. Opt. 10 (2008) 075101.

[11] W. Blau, H. Byrne, W.M. Dennis, J.M. Kelly, Opt. Commun. 56 (1985) 25.

[12] K. Mansour, M.J. Soileau, E.W. Van Stryland, J. Opt. Soc. Am. A 9 (1992) 1100.

[13] W.J. Blau, H.J. Byrne, D.J. Cardin, T.J. Dennis, J.P. Hare, H.W. Kroto, R. Taylor, D.R.M. Walton, Phys. Rev. Lett. 67 (1991) 1423.

[14] L.W. Tutt, A. Kost, Nature 356 (1992) 225.

[15] L. Vivien, P. Lancon, D. Riehl, F. Hache, E. Anglaret, Carbon 40 (2002) 1789.

[16] J. Wang, W.J. Blau, Appl. Phys. B 91 (2008) 521.

[17] J. Wang, W.J. Blau, J. Phys. Chem. C 112 (2008) 2298.

[18] J. Wang, Y. Hernandez, M. Lotya, J.N. Coleman, W.J. Blau, Adv. Mater. (2009).

[19] N. Izard, C. Menard, D. Riehl, E. Doris, C. Mioskowski, E. Anglaret, Chem. Phys. Lett. 391 (2004) 124.

[20] S. Webster, M. Reyes-Reyes, X. Pedron, R. López-Sandoval, M. Terrones, D.L. Carroll, Adv. Mater. 17 (2005) 1239.

[21] E.M. Ni Mhuircheartaigh, S. Giordani, W.J. Blau, J. Phys. Chem. B 110 (2006) 23136.

[22] Z.B. Liu, J.G. Tian, Z. Guo, D.M. Ren, F. Du, J.Y. Zheng, Y.S. Chen, Adv. Mater. 20 (2008) 511.

[23] J. Wang, W.J. Blau, Chem. Phys. Lett. 465 (2008) 265.

[24] F. D'Souza, R. Chitta, A.S.D. Sandanayaka, N.K. Subbaiyan, L. D'Souza, Y. Araki, O. Ito, J. Am. Chem. Soc 129 (2007) 15865.

[25] W. Wu, H. Zhu, L. Fan, S. Yang, Chem. Eur. J. 14 (2008) 5981.

[26] K.-S. Liao, A. Wan, J.D. Batteas, D.E. Bergbreiter, Langmuir 24 (2008) 4245. 
[27] E.P. Dillon, C.A. Crouse, A.R. Barron, ACS Nano 2 (2008) 156.

[28] A. Hirsch, Q. Li, F. Wudl, Angew. Chem. Int. Ed. Engl. 30 (1991) 1309.

[29] E.V. Basiuk, M. Monroy-Pelaez, I. Puente-Lee, V.A. Basiuk, Nano Lett. 4 (2004) 863.

[30] Z. Gasyna, P.N. Schatz, J.P. Hare, T.J. Dennis, H.W. Kroto, R. Taylor, D.R.M. Walton, Chem. Phys. Lett. 183 (1991) 283.

[31] S. Curran, A.P. Davey, J. Coleman, A. Dalton, B. McCarthy, S. Maier, A. Drury, D. Gray, M. Brennan, K. Ryder, M.L. de la Chapelle, C. Journet, P. Bernier, H.J. Byrne, D. Carroll, P.M. Ajayan, S. Lefrant, W. Blau, Synth. Met. 103 (1999) 2559. 


\section{Captions for Figures and Table}

Figure 1. Synthesis of DWNT-PEI10,000- $\mathrm{C}_{60}$

Figure 2. TGA of DWNT, DWNT-PEI10,000, DWNT-PEI10,000-C 60 in Ar and DWNT-PEI10,000-C 60 in $\mathrm{Ar}$ followed by air introduced at $500{ }^{\circ} \mathrm{C}$

Figure 3. UV-vis spectra of $\mathrm{C}_{60}$, DWNT-PEI10,000 and DWNT-PEI10,000- $\mathrm{C}_{60}$ in chlorobenzene

Figure 4. TEM images of a pristine TWNT partially covered with carbon materials (left) and a SWNTFullerene hybrid (right). The circular profiles indicated by the arrows suggest that monomeric $\mathrm{C}_{60}$ molecules (based on their size and shape) are attached to the inner and outer surfaces of the nanotube.

Figure 5. Plots of normalized transmission and scattering light against incident pulse energy density for DWNT-Fullerene dispersions.

Figure 6. Optical limiting responses of the DWNT-Fullerene, Fullerene and SWNTs

Table 1. Linear and NLO coefficients for the DWNT-Fullerene, Fullerene and SWNTs. 


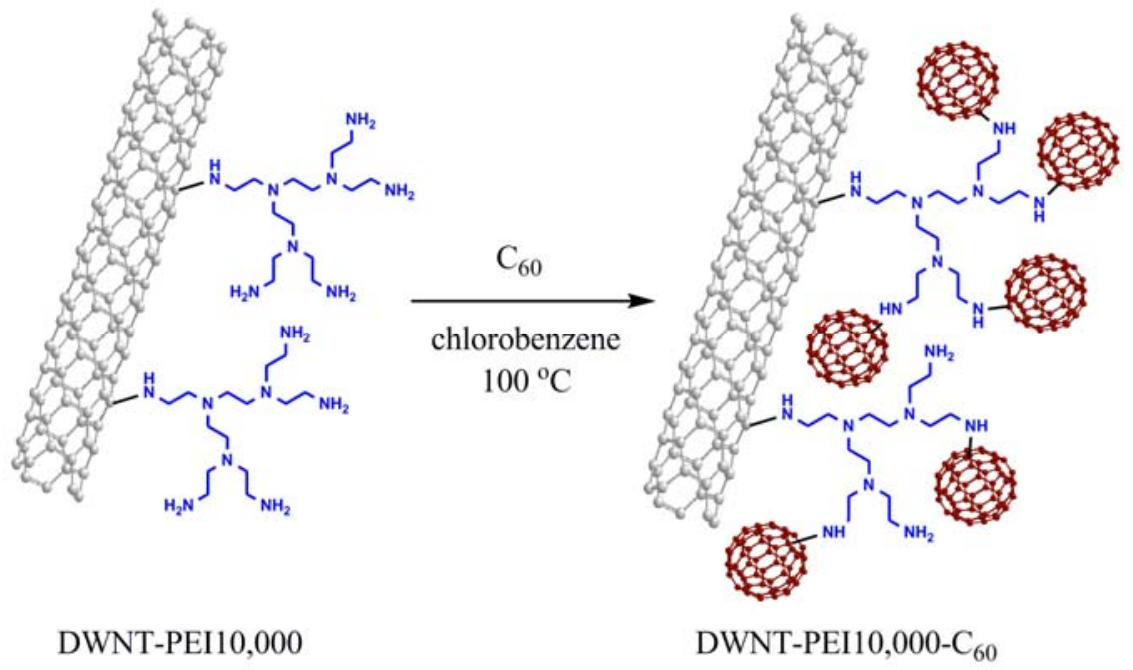

Figure 1. 


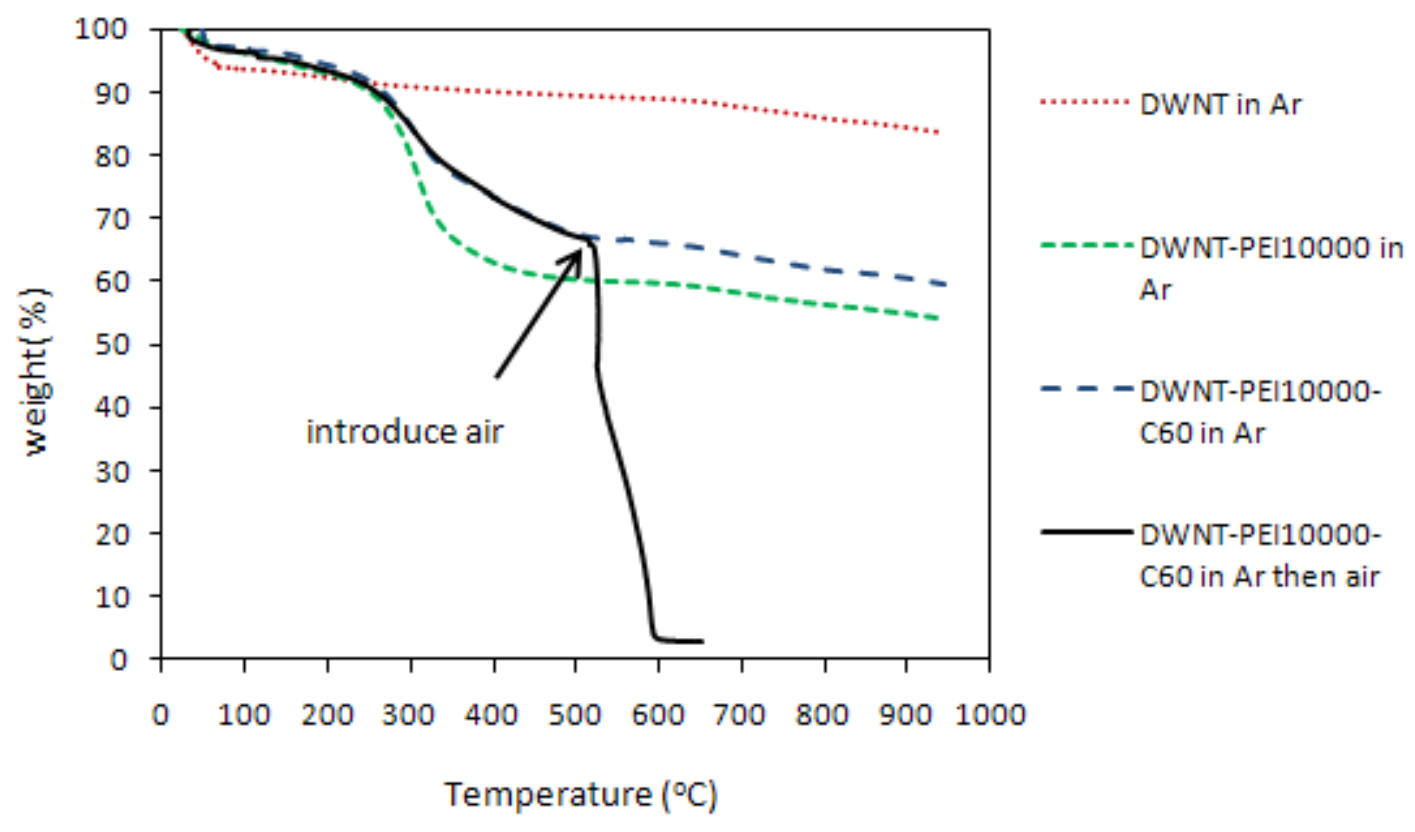

Figure 2. 


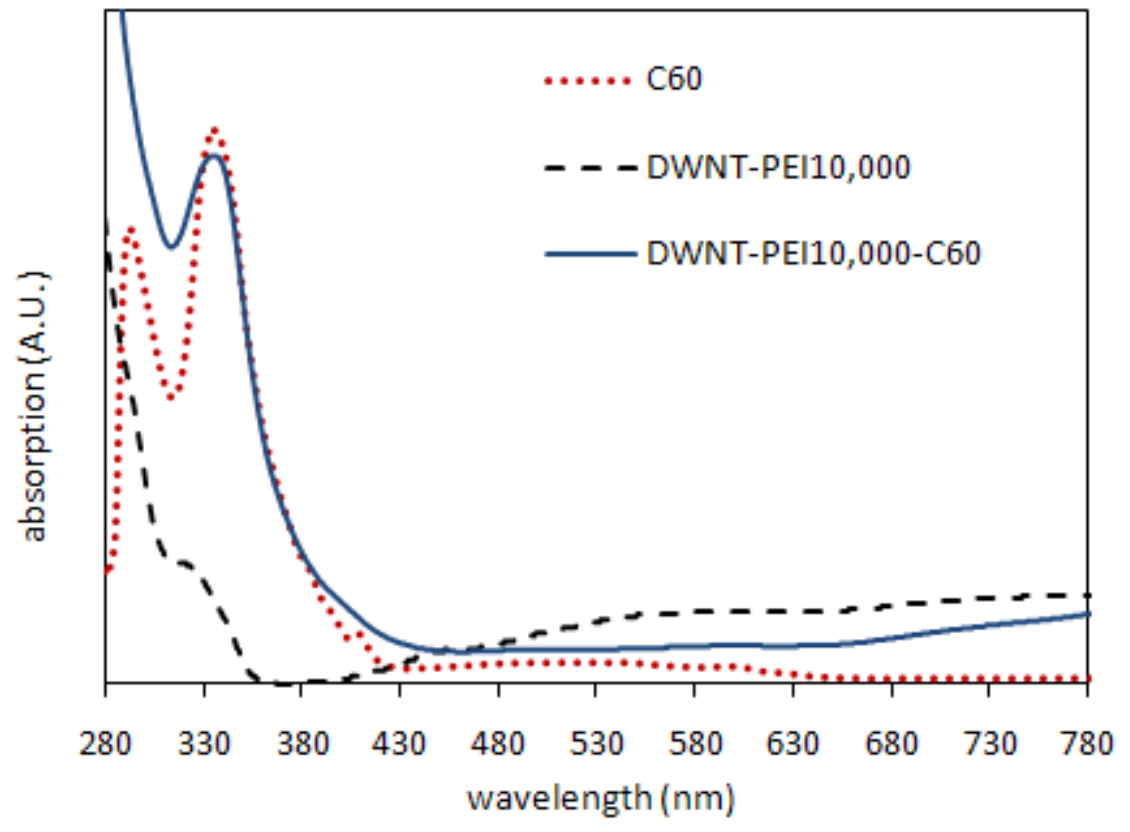

Figure 3. 

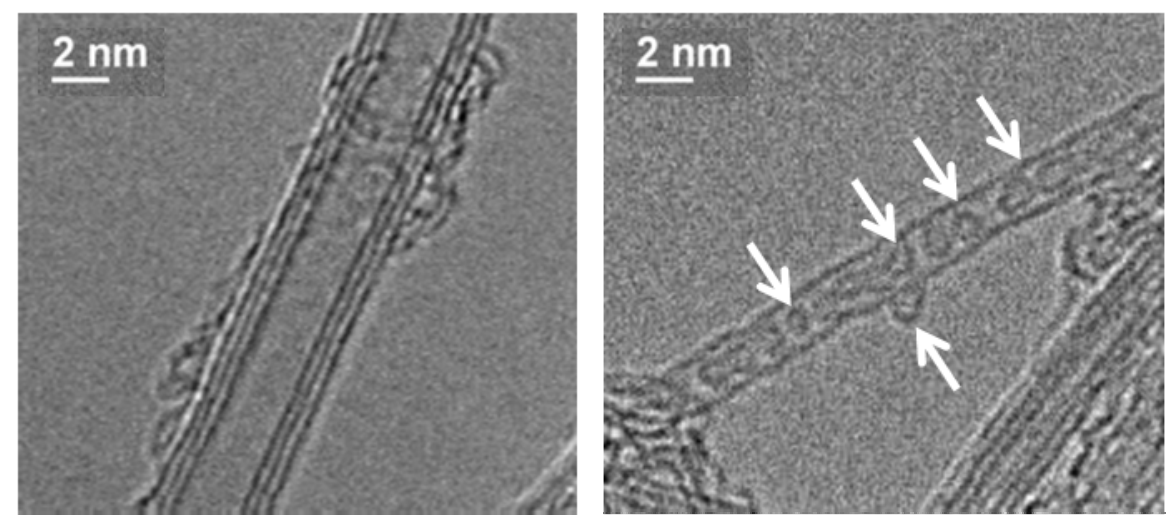

Figure 4. 


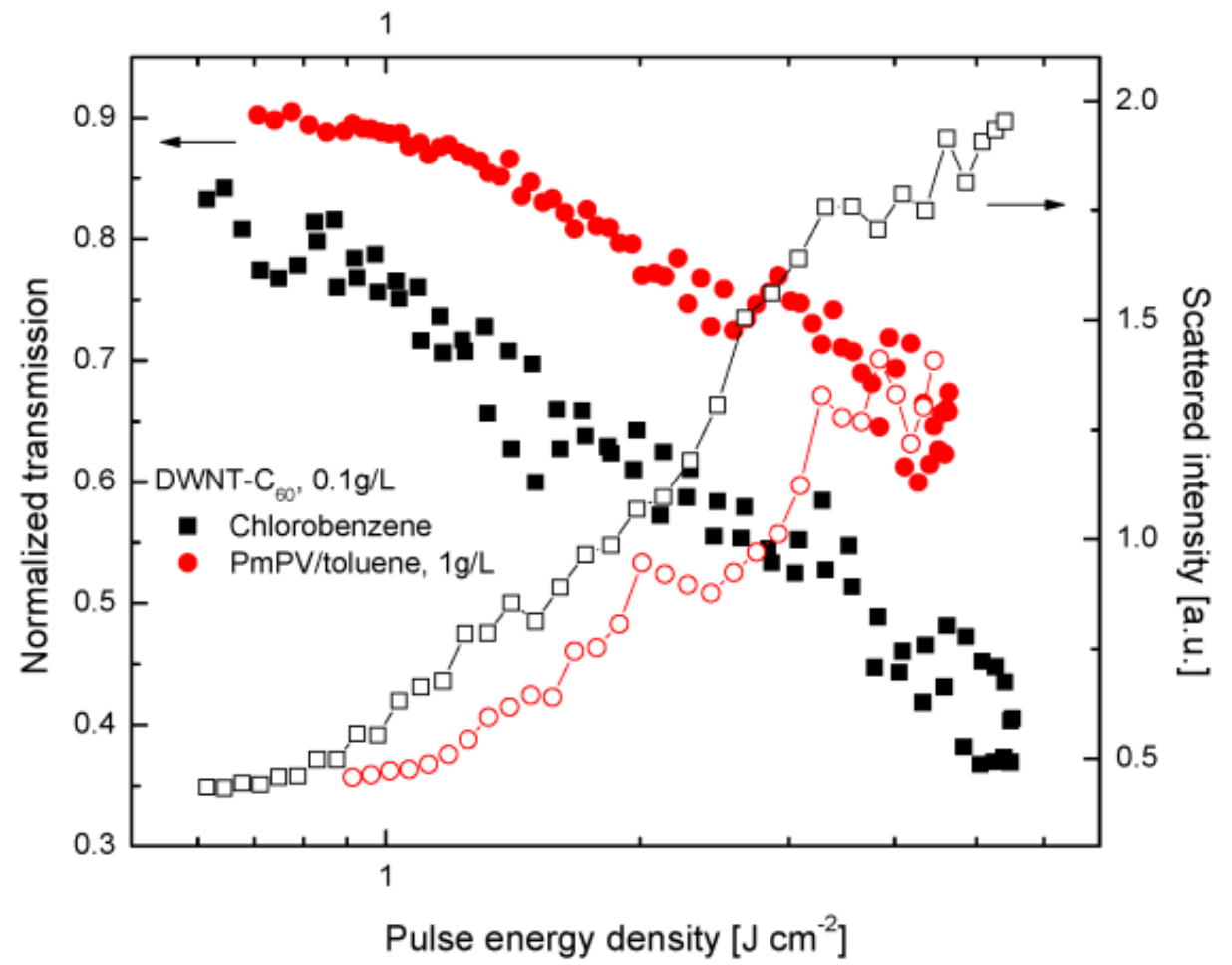

Figure 5. 


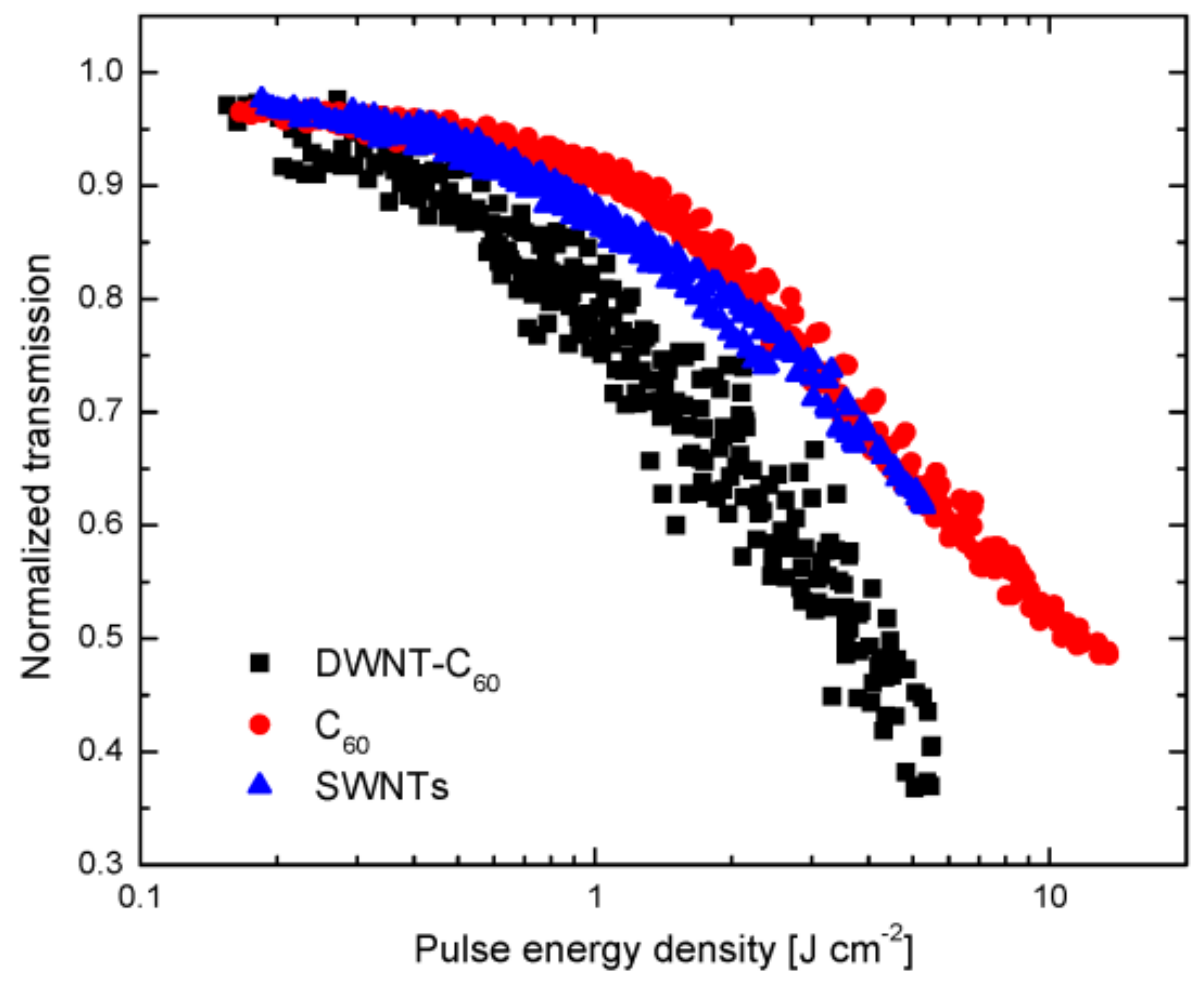

Figure 6. 


\begin{tabular}{|c|c|c|c|c|c|c|}
\hline Material & Host & $\begin{array}{l}\text { Conc. } \\
(\mathrm{g} / \mathrm{L})\end{array}$ & $\begin{array}{c}\mathrm{T} \\
(\%)\end{array}$ & $\begin{array}{c}\alpha_{0} \\
\left(\mathrm{~cm}^{-1}\right)\end{array}$ & $\begin{array}{c}\beta_{\text {eff }} \\
\left(\mathrm{cm} \mathrm{GW}^{-1}\right)\end{array}$ & $\begin{array}{c}\operatorname{Im}\left\{\chi^{(3)}\right\} \\
\left(\mathrm{x} 10^{-12} \mathrm{esu}\right)\end{array}$ \\
\hline & Chlorobenzene & 0.1 & 79.8 & 0.23 & $7.01 \pm 0.99$ & $2.74 \pm 0.39$ \\
\hline \multicolumn{7}{|c|}{ DWNT-C $_{60}$} \\
\hline & PmPV/toluene & 0.1 & 83.4 & 0.18 & $4.01 \pm 1.15$ & $1.51 \pm 0.43$ \\
\hline SWNTs & $\mathrm{DMF}$ & 0.005 & 81.3 & 0.21 & $2.46 \pm 0.50$ & $0.85 \pm 0.17$ \\
\hline $\mathrm{C}_{60}$ & Toluene & 0.11 & 81.9 & 0.20 & $3.28 \pm 0.51$ & $1.24 \pm 0.19$ \\
\hline
\end{tabular}

Table 1. 